\title{
The Rotator Interval - A Link Between Anatomy and Ultrasound
}

\section{두(ㅇ)(ㄱ) (요}

\author{
Authors \\ Giorgio Tamborrini1, 7, Ingrid Möller2, 7, David Bong'3, 7, Maribel Miguel4, Christian Marx', Andreas Marc Müller5, \\ Magdalena Müller-Gerb|6
}

\begin{abstract}
Affiliations
1 Ultrasound Center, Rheumatology, Basel, Switzerland

2 Instituto Poal de Reumatologia, BCN Sonoanatomy group, Barcelona, Spain

3 BCN Sonoanatomy group, Rheumatology, Barcelona, Spain

4 Departamento de Patología y Terapéutica Experimental University of Barcelona, Barcelona, Spain

5 Orthopädie und Traumatologie, Universitatsspital Basel, Basel, Switzerland

6 Institute of Anatomy, Universitat Basel, Basel, Switzerland

7 EULAR Study Group on Anatomy for the Image
\end{abstract}

Key words

shoulder, rotator cuff, interval

received 11.08 .2016

revised 24.02.2017

accepted 23.04.2017

Bibliography

DOI https://doi.org/10.1055/s-0043-110473

Ultrasound Int Open 2017; 3: E107-E116

(c) Georg Thieme Verlag KG Stuttgart · New York

ISSN 2199-7152

\author{
Correspondence \\ Dr. med. Giorgio Tamborrini \\ Ultrasound Center Rheumatology \\ Aeschenvorstadt 68 \\ 4051 Basel \\ Switzerland \\ Tel.: +41/612/251010 \\ shoulder@irheuma.ch
}

\section{ABSTRACT}

Shoulder pathologies of the rotator cuff of the shoulder are common in clinical practice. The focus of this pictorial essay is to discuss the anatomical details of the rotator interval of the shoulder, correlate the anatomy with normal ultrasound images and present selected pathologies. We focus on the imaging of the rotator interval that is actually the anterosuperior aspect of the glenohumeral joint capsule that is reinforced externally by the coracohumeral ligament, internally by the superior glenohumeral ligament and capsular fibers which blend together and insert medially and laterally to the bicipital groove. In this article we demonstrate the capability of high-resolution musculoskeletal ultrasound to visualize the detailed anatomy of the rotator interval. MSUS has a higher spatial resolution than other imaging techniques and the ability to examine these structures dynamically and to utilize the probe for precise anatomic localization of the patient's pain by sono-palpation.

\section{Introduction}

Shoulder pathologies in the anterolateral region of the rotator cuff of the shoulder are common in clinical practice. Frequently encountered pathologies in this region are listed in $\mathbf{r}$ Table 1 . Detailed knowledge of the anatomy of this region and its ultrasound appearance is essential to recognize possible pathologies that correlate with the clinical presentation [1]. The focus of this pictorial essay is to review and discuss the anatomical details of the rotator interval of the shoulder, correlate the anatomy with normal ultrasound images and present selected pathologies.

Diagnostic musculoskeletal ultrasound (MSUS) is an excellent tool in the detection of rotator cuff (RC) pathologies [2,3] with an accuracy compared to magnetic resonance imaging (MRI) and arthroscopy in the hands of experienced sonographers [4-8]. RC lesions are even more frequent in inflammatory patients (e. g., in rheumatoid arthritis (RA), crystal deposition diseases or polymyalgia rheumatica) with the result that a painful shoulder is not always related to active synovitis [9].

The rotator cuff interval (RI) is a roughly triangular region created by the interposition of the coracoid process, the base of the triangle, between the subscapularis muscle/tendon (SSC) medially and the supraspinatus muscle/tendon (SSP) anteriorly forming the two sides. The RI is a complex anatomic region that plays a relevant role in the stability and function of the shoulder joint. The structure of the RI supports the tendon of the long head of the biceps muscle to prevent dislocation antero-medially and antero-inferiorly (e. g., in external rotation and abduction). In addition, RI structures contribute to inferior glenohumeral joint stability by limiting glenohumeral motility $[10,11]$. The added value of the ultra- 
sound assessment is to provide a dynamic complementary tool to help in the clinical approach of a patient with RI injuries [12,13].

\section{Anatomy}

The RC is composed of the tendons of the supraspinatus (SSP), infraspinatus (ISP), subscapularis (SSC) and teres minor (Tm) muscles. The RC is an important dynamic stabilizer of the glenohumeral joint; it compresses the humeral head into the glenoid and thus prevents superior migration of the humeral head triggered by del-

- Table 1 adapted from [42-1], frequently encountered pathologies related to anatomical regions.

\begin{tabular}{|l|l|}
\hline Anatomical region & Pathologies \\
\hline $\begin{array}{l}\text { Long biceps tendon } \\
\text { (LBT) }\end{array}$ & $\begin{array}{l}\text { Tendinosis, tears, effusion in the LBT } \\
\text { recess, calcifications, (sub-) luxation }\end{array}$ \\
\hline $\begin{array}{l}\text { Supraspinatus and } \\
\text { subscapularis tendon }\end{array}$ & $\begin{array}{l}\text { Tendinosis, tears, enthesopathy, } \\
\text { calcifications, etc. }\end{array}$ \\
\hline $\begin{array}{l}\text { Ligaments, labrum and } \\
\text { joint capsule }\end{array}$ & $\begin{array}{l}\text { Tears, thickening, contraction (e. g., in } \\
\text { capsulitis), anteromedial or anterosuperior } \\
\text { impingement, secondary instability, etc. }\end{array}$ \\
\hline Bursa & $\begin{array}{l}\text { Bursitis (subdeltoid, subcoracoid, } \\
\text { subscapularis communicating with the } \\
\text { anterior gleno-humeral recess) }\end{array}$ \\
\hline
\end{tabular}

toid muscle contraction during abduction and elevation [14]. It may also prevent excessive anterior translation of the humeral head in abduction and external rotation [15]. The triangular shaped RI forms a unique gap in the anterior part of the RC and may vary in size [16].The RI is actually the anterosuperior aspect of the glenohumeral joint capsule that is reinforced externally (laterally) by the coracohumeral ligament ( $\mathrm{CHL})$, internally (medially) by the superior glenohumeral ligament (SGHL) and capsular fibers which blend together and insert medially and laterally to the bicipital groove (॰ Fig. 1-4).

\section{$\mathrm{CHL}$ (Coracohumeral Ligament)}

The $\mathrm{CHL}$ originates at the proximal third of the dorsolateral aspect of the base of the coracoid [17]. The CHL consists of a lateral and medial bundle arranged like two pillars of a bridge. The smaller medial bundle $(\mathrm{MCHL})$ crosses the intraarticular part and surrounds the medial and inferior part of the intraarticular portion of the LBT to insert at the lesser tubercle together with the superior fibers of the SSC tendon and the SGHL [18-21]. This part communicates with the glenohumeral ligament and the superior part with the SSC tendon and forms the medial-pulley-complex (MPC) [21]. This anatomical relationship explains why the LBT tends to become dislocated antero-medially with a subscapularis tendon tear. The larger lateral bundle (LCHL) surrounds the superior and lateral part of the intraarticular LBT. The LCHL inserts at the greater tubercle of the humerus and on the anterior border of the SSP and forms the lateral-pul-

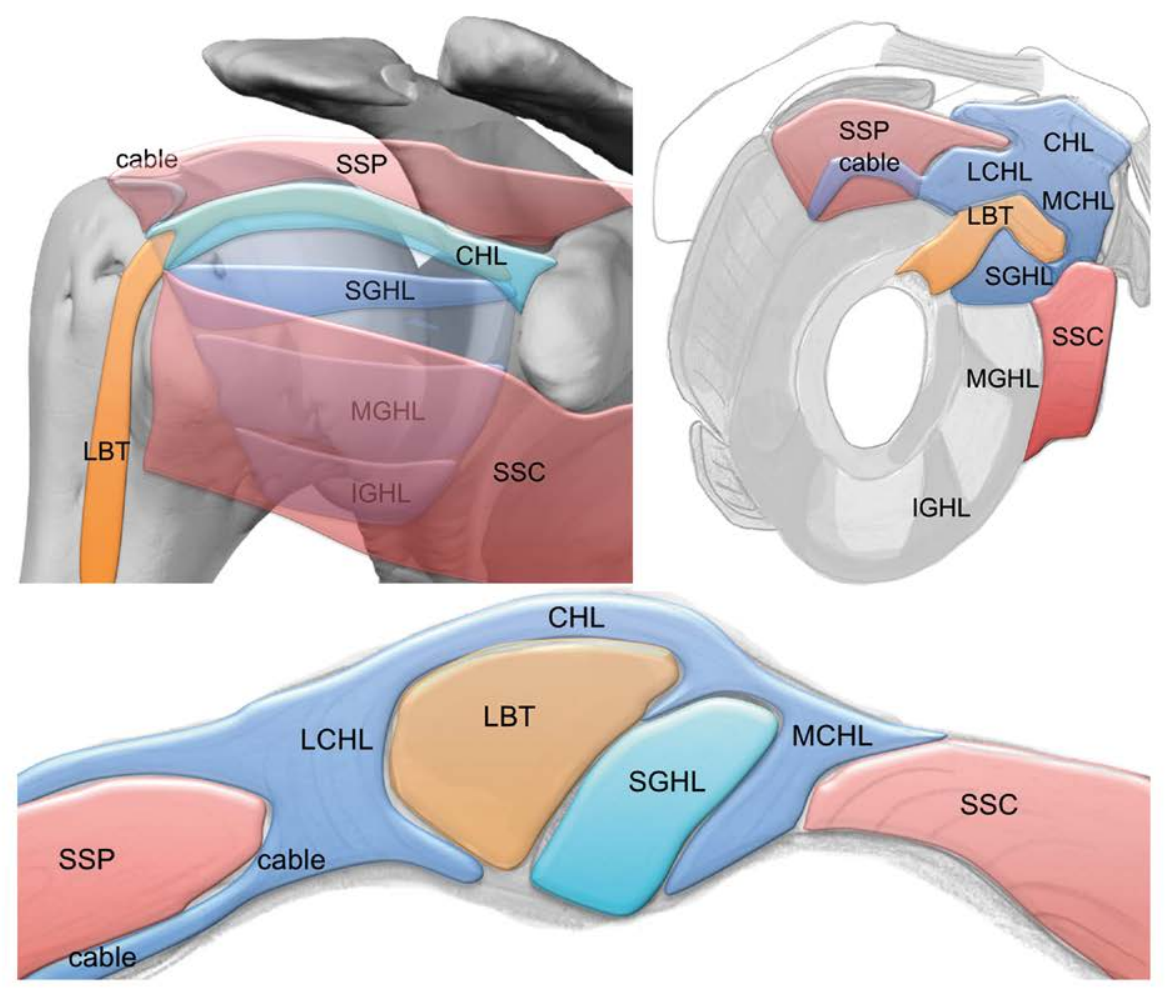

- Fig. 1 Drawings of the rotator interval. Superior glenohumeral ligament (SGHL), middle glenohumeral ligament (MGHL), anterior inferior glenohumeral ligament (IGHL), coracohumeral ligament (CHL), medial coracohumeral ligament (MCHL), Lateral coracohumeral ligament (LCHL), subscapularis tendon (SSC), long biceps tendon (LBT) and supraspinatus tendon (SSP). 
ley-complex (LPC) [22, 23]. This lateral part has been called the rotator cable, a thin fibrous band continuous with the coracohumeral ligament (and some fibers of the SGHL) that arcs along the undersurface of the SSP and ISP fibers and superficial to the joint capsule. The CHL may be hypoplastic or absent in up to $6 \%$ of shoulder dissections [24]. The tension of the CHL has an important effect on the stability and range of motion of the glenohumeral joint, particularly in external rotation [10,22]. The CHL consists of loose connective tissue and is therefore relatively flexible. Histological studies demonstrate that the $\mathrm{CHL}$ contains irregular and sparse fibers with a higher proportion of type III collagen compared to the LBT or the intramuscular SSC tendon $[25,26]$. Selected histological studies even suggest that the superior glenohumeral ligament may be a defined part of the CHL, adherent to the tendinous slip of the SSC [27].

\section{SGHL (Superior Glenohumeral Ligament)}

The SGHL is a reinforcement of the anterosuperior glenohumeral joint capsule. Some anatomical details and variations of the SGHL need to be explained in more detail due to their relevance in imaging studies. The SGHL may be absent in up to $3 \%$ of patients based on arthroscopy findings [28]. The proximal attachment of the SGHL can be quite variable: originating from the LBT only; from the LBT and the superior part of the labrum; or from the middle glenohumeral ligament, the LBT, the superior part of the labrum and partially from the superior glenoid tubercle of the scapula [29, 30]. It inserts near the lesser tubercle at the fovea capitis of the humerus [10]. The SGHL crosses the floor of the RI and may fuse with the MCHL [23].

\section{LBT (Long Biceps Tendon) and Borders of the RI (Rotator Interval)}

The RI contains the intraarticular portion of the tendon of the long head of the biceps muscle (LBT) as it passes through the joint capsule [17-20]. The LBT may originate from the postero-superior labrum, the superior glenoid tubercle, or from both [31-21]. At this level, the LBT functions as a humeral head depressor and stabilizer of the glenohumeral joint. In 207 examined shoulders, the mean width of the long head of the biceps tendon was $6.0 \mathrm{~mm}$ (range: 3-10 mm) [32].The distal anterior roof of the RI expands anteriorly to form the transverse humeral ligament, which covers the LBT in the bicipital groove. Some authors propose that the transverse ligament is only a minor contributor to stabilization of the LBT in the bicipital groove $[33,20,34]$, while others describe no distinct transverse ligament, characterizing it as a combination of fibers from the SSC tendon and the posterior lamina of the tendon of the pectoralis major muscle [35]. Furthermore, the supraspinatus tendon has an aponeurotic tendon-like expansion which courses anteriorly and laterally to the LBT tendon reaching the cranial insertion of the pectoralis major. It may be identified with MRI or ultrasound in about one-half of shoulders [36]. Fibers from the coracohumeral ligament, SSP and SSC contribute to the anterior roof proximal to the transverse ligament, forming a sling around the biceps tendon at the level of the proximal bicipital groove while forming the distal end or the apex of the RI [37]. Thus the RI contains parts of the $\mathrm{CHL}$ (posterior roof and lateral wall together with

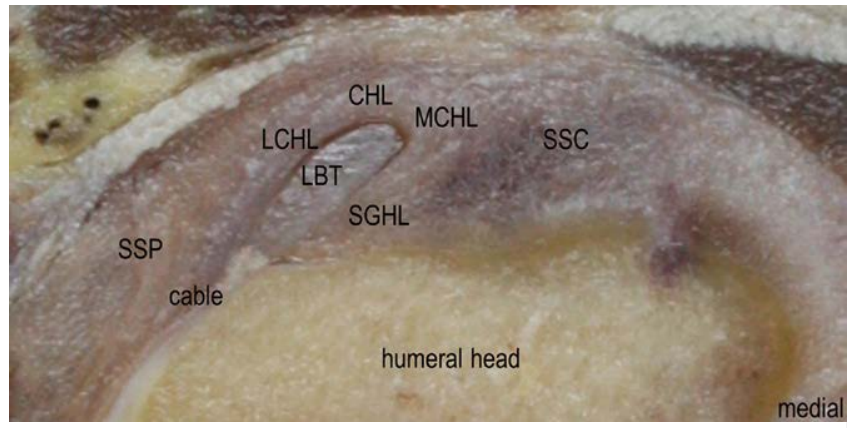

- Fig. 2 Anatomical section through the rotator interval showing the superior glenohumeral ligament (SGHL), the medial (MCHL) and lateral ( $\mathrm{LCHL}$ ) coracohumeral ligament $(\mathrm{CHL})$, the long biceps tendon (LBT), the supraspinatus tendon (SSP) and the subscapularis tendon (SSC).

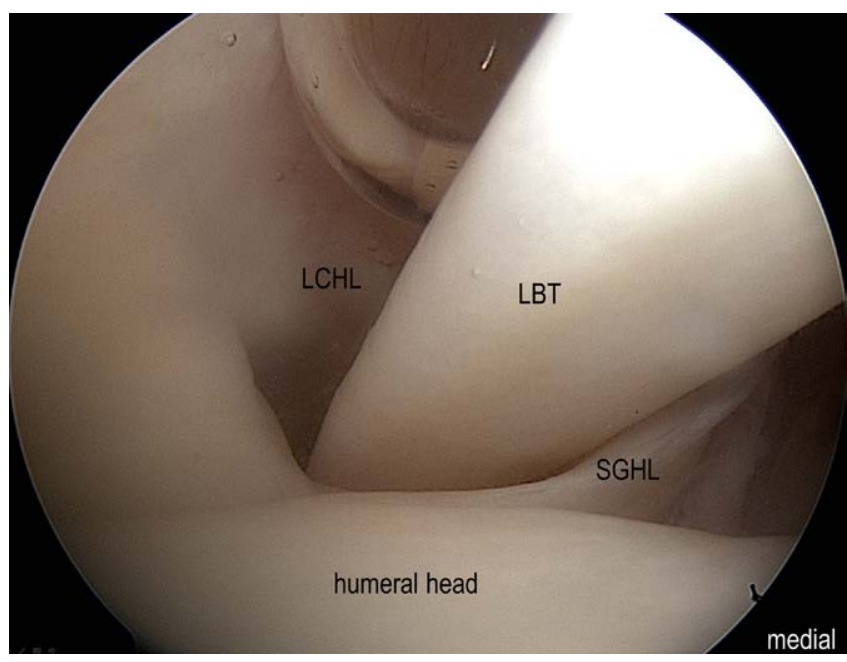

- Fig. 3 Arthroscopic image showing the long biceps tendon (LBT), the superior glenohumeral ligament (SGHL) and the lateral bundle of the coracohumeral ligament (LCHL).

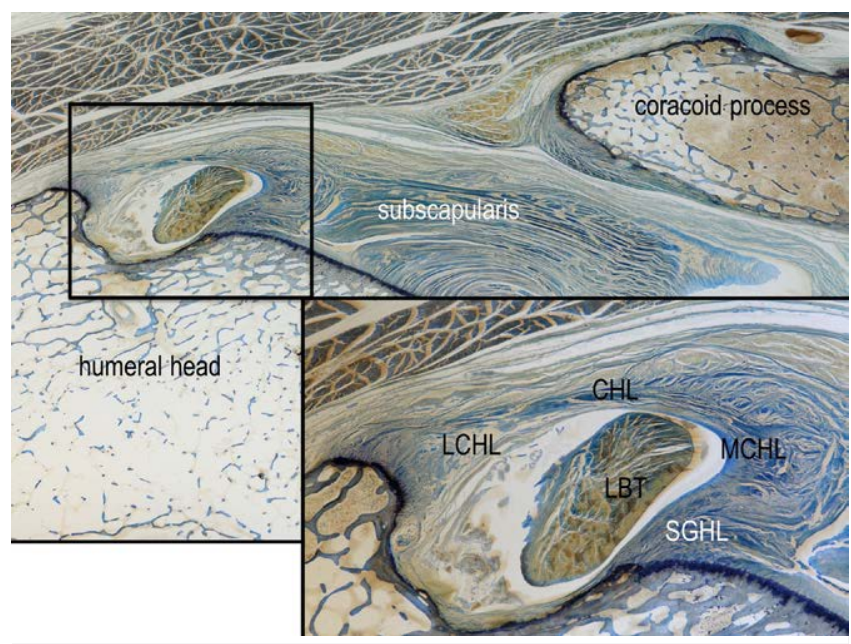

- Fig. 4 Histological image (toluidine blue) of the rotator interval showing the long biceps tendon (LBT), the superior glenohumeral ligament (SGHL) and the lateral ( $\mathrm{LCHL}$ ) and medial (MCHL) coracohumeral ligament (CHL). 

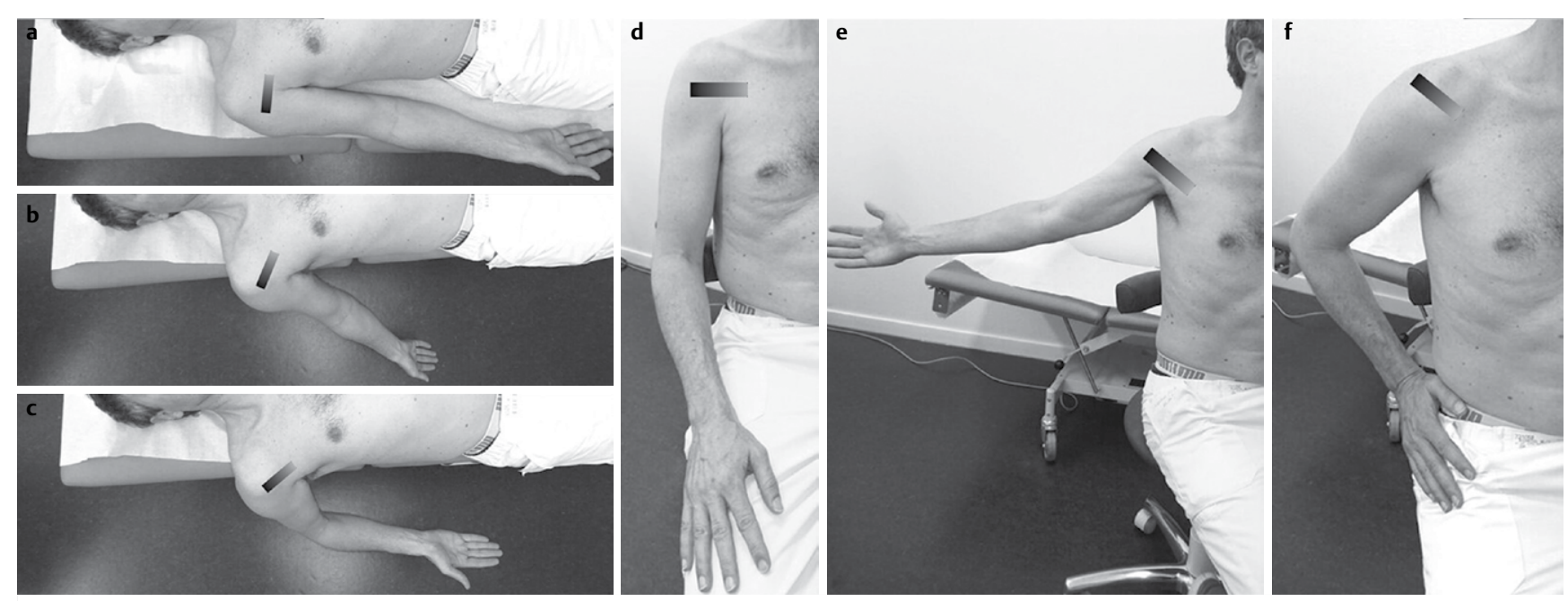

- Fig. 5 Patient in supine position, arm in neutral position: a; arm in retroversion: b; arm in retroversion and slightly external rotation: c; patient in a sitting position. Arm in neutral position: $\mathbf{d}$; in external rotation and abduction: $\mathbf{e}$; in the modified Crass position: $\mathbf{f}$.

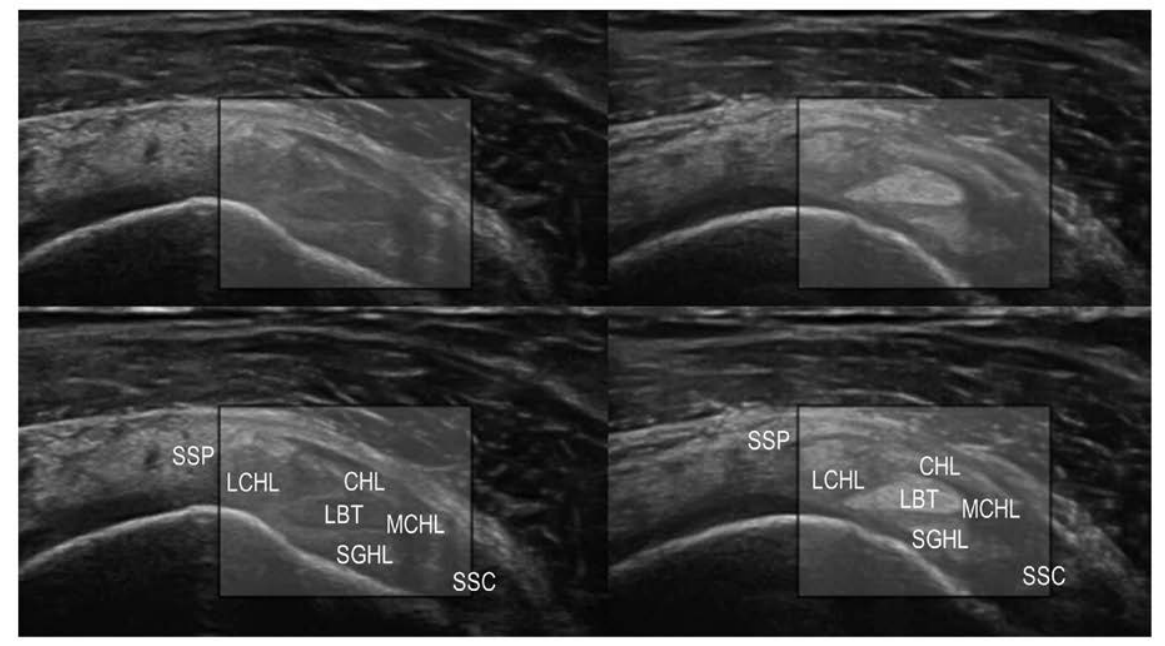

- Fig. 6 Transverse oblique ultrasound image of the rotator interval in a modified Crass position demonstrating an anisotropy effect (box) of the long biceps tendon (LBT), of the superior glenohumeral ligament $(\mathrm{SCHL})$ and of the medial (MCHL) and lateral ( $\mathrm{LCHL}$ ) coracohumeral ligament (CHL), subscapularis tendon (SSC), supraspinatus tendon (SSP).

the SSP tendon) and the SGHL (medial wall together with fibers of the SSC tendon) ( $\triangleright$ Fig. 2). They form the sling-like capsulo-ligamentous biceps pulley (CHL, SGHL, capsule) [38] ( $>$ Fig. 3). All of these structures together are also referred to as the superior-complex layer (SCL) [39]. Superiorly and posteriorly, the RI border is formed by fibers of the SSP, inferiorly by fibers of the SSC. Between the rotator cable and the insertional region of the distal portion of the SSP at the greater tubercle, there is a zone known as the rotator crescent which is a poorly vascularized but clinically highly stressed section of the rotator cuff. The crescent of the rotator cuff becomes thinner with age. Tears involving the rotator crescent with an intact rotator cuff cable may have minimal biomechanical consequences [12] [40]. The rotator cable has been described as the suspension bridge of the shoulder joint providing stress dispersal to the rotator cuff tendons and is a stabilizer of the glenohumeral joint [12]. Morag et al. measured the different rotator cuff structures around the cable on cadaveric specimens by ultrasound [41,42]. Ultrasound demonstrates the rotator cable on essentially all normal shoulders consistent with the articular-sided fibrillary structure perpendicular to the rotator (SSP, ISP) noted in histologic studies [42].

\section{Ultrasound Technique and Ultrasound Findings}

Before focusing on the RI, the full extent of the biceps tendon (LHBT) and its associated structures are initially examined in transverse and longitudinal axes from the RI distal to the superior aspect of the tendon of the pectoralis major [43]. 


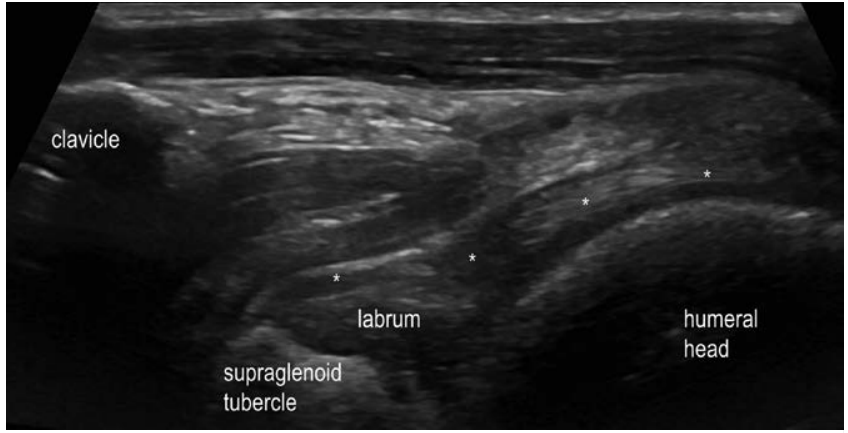

- Fig. 7 Longitudinal oblique ultrasound image of the origin of the long biceps tendon (asterisks) in a modified Crass position with forced internal rotation.

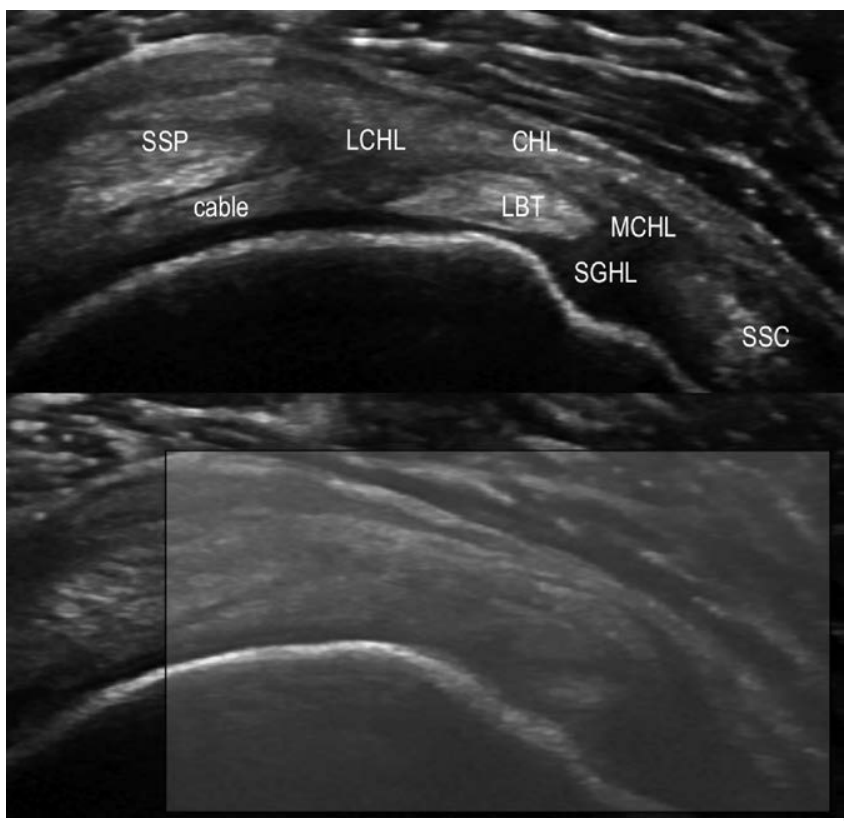

- Fig. 8 Transverse oblique ultrasound image of the rotator interval in a relaxed neutral position with flexed elbow and supinated forearm demonstrating an anisotropy effect (box at the bottom) of the long biceps tendon (LBT) and of the superior glenohumeral ligament (SGHL), subscapularis tendon (SSC), supraspinatus tendon (SSP) and of the medial $(\mathrm{MCHL})$ and lateral $(\mathrm{LCHL})$ coracohumeral ligament $(\mathrm{CHL})$.

For the examination of the rotator interval, one preferred position to examine the patient is supine on the examination table with the upper extremity to be examined hanging off the side of the table (allowing for posterior flexion which opens the interval, stretches the LHBT and tightens the $\mathrm{CHL}$ ) and in neutral rotation - Fig. 5a-c. Alternatively, the patient sits on a revolving chair with the examiner sitting or standing behind or in front of the patient according to personal preference ( $\vee$ Fig. $5 \mathbf{d}-\mathbf{f}$ ).

We begin by placing the probe in short axis over the superior aspect of the bicipital groove. The probe is then moved upward to a position just above the most proximal aspect of the groove (and the trans-humeral ligament). It is now in the most distal aspect of the $\mathrm{RI}$ where the $\mathrm{CHL}$ and SGHL coalesce into an annular sling around the LHBT as it enters the glenohumeral joint. The sling is

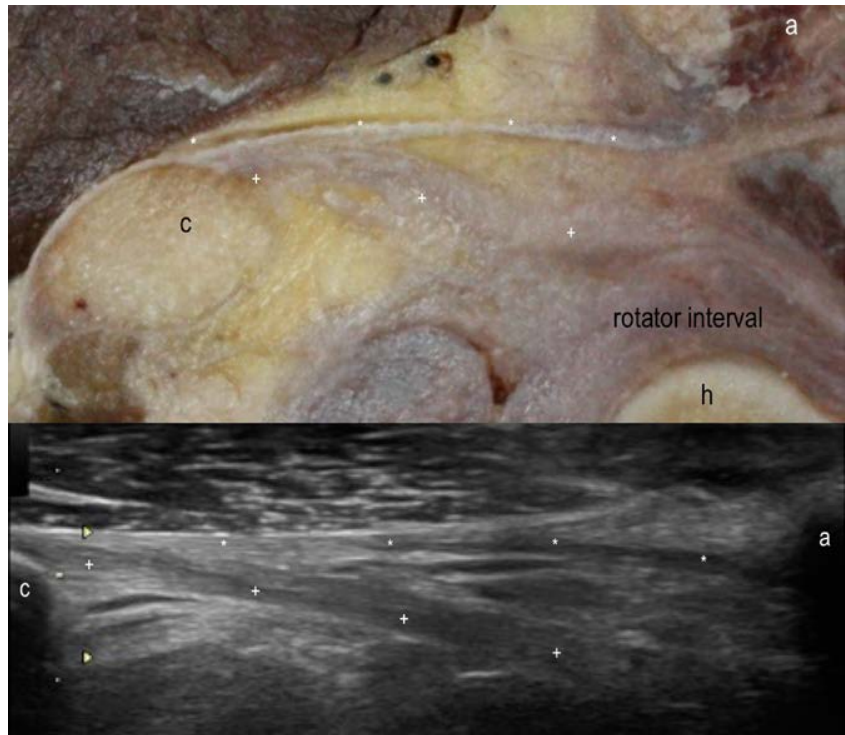

- Fig. 9 Anatomical section anterior oblique showing the coracoacromial ligament (asterisks) and the coracohumeral ligament (plus signs) in an external rotation and retroversion position, coracoid process (c), acromion (a).

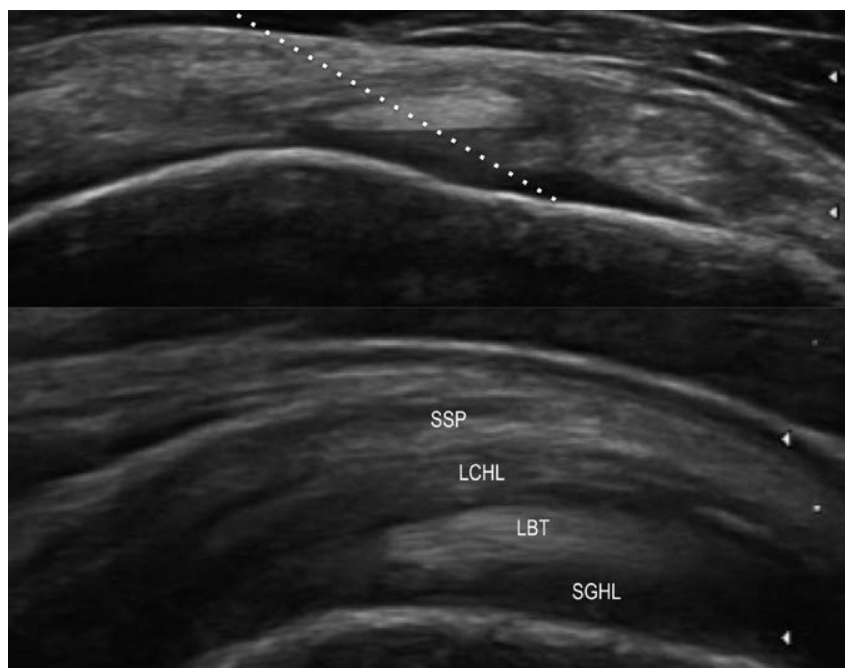

- Fig. 10 Ultrasound images of the rotator interval in a transverse view (at the top) and longitudinal oblique view (at the bottom) in a modified Crass position. Superior glenohumeral ligament (SGHL), lateral coracohumeral ligament (LCHL), long biceps tendon (LBT), supraspinatus tendon (SSP).

hypoechoic when compared to the hyperechoic LHBT and the probe must be angulated from side-to-side to eliminate this anisotropy $>$ Fig. 6. Remember that the LHBT is much more sensitive to the angulation of the probe than the CHL. The LHBT/CHL are followed superiorly as they enter the joint and with the LHBT turning sharply and disappearing into the joint towards its origin on the supraglenoid tubercle $>$ Fig. 7. It is possible to visualize the LHBT/CHL over the most distal cartilaginous surface of the humeral head. It is important to toggle the probe slightly to utilize the different anisotropies of the LHBT and CHL to distinguish them as distinct structures separated by the joint capsule $>$ Fig. 8 . 


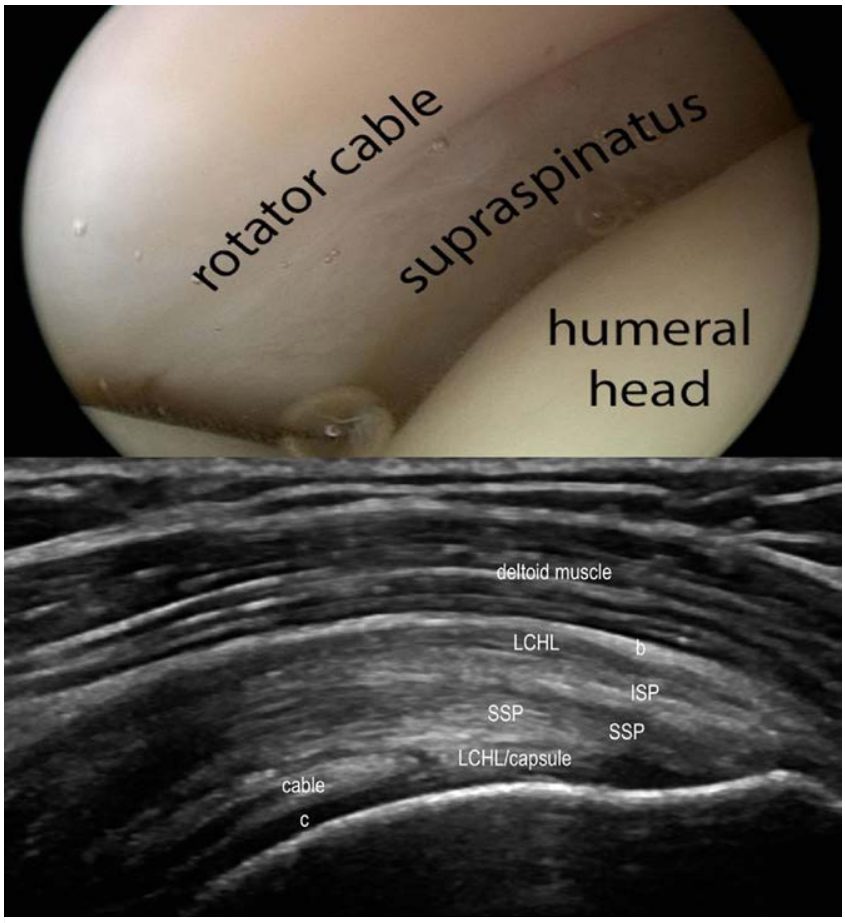

- Fig. 11 Arthroscopy of the rotator cable and ultrasound image of the supraspinatus tendon longitudinal in a modified Crass position: peribursal structures (b), layer I = superficial layer, measuring $1 \mathrm{~mm}$ in thickness and composed of fibers from the coracohumeral ligament (LCHL) which extends posteriorly and obliquely, infraspinatus and supraspinatus tendon layer (ISP and SSP, respectively) composed of 3 layers: layer II= densely packed fibers of the tendon, $3-5 \mathrm{~mm}$ in thickness, layer III $=3 \mathrm{~mm}$ thick and composed of smaller bundles of collagen which are loosely organized at an approximately 45 degree angle to the long axis of the tendon, layer IV = loose connective tissue and thick collagen bands and merges with fibers from the coracohumeral ligament), layer $\mathrm{V}(\mathrm{LCHL} /$ capsule $)$ = capsule and glenohumeral ligament, $2 \mathrm{~mm}$ in thickness, cartilage (c). Note the anisotropy effect at the insertion due to the different trajectories of the different layers. Anisotropy artifacts typically affect the insertional area at the level of the footprint of the humeral head. To avoid these artifacts, try to tilt the probe laterally to have the ultrasound beam as perpendicular as possible to the tendon or the ligament fibers.
Returning to the starting point for transverse imaging of the RI, the dependent arm is slightly rotated internally and externally and the proximal pole of the probe is rotated approximately $30^{\circ}$ in the direction of the deep aspect of the lateral coracoid process and the $\mathrm{CHL}$ origin. The oblique probe is now longitudinal to the $\mathrm{CHL}$ and essentially transverse to the distal SSP tendon close to its insertion into the medial aspect of the greater tuberosity. One should visualize the trajectory of the fibers of the $\mathrm{CHL}$ originating at the base of the lateral coracoid process as they pass over the LHBT into the inferior portion of the SSP > Fig. 9 [44].
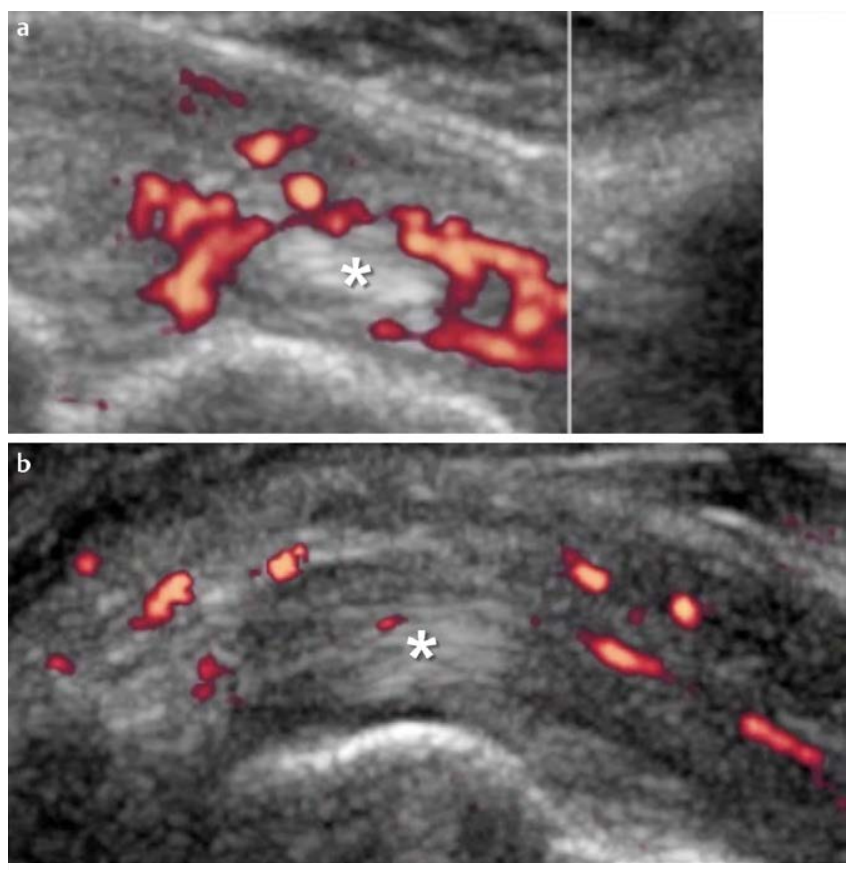

- Fig. 12 Adhesive capsulitis phase 1. Transverse a and longitudinal oblique b power Doppler images in a modified Crass position obtained over the rotator cuff interval. Images show the normal long head of the biceps tendon (asterisks) that appears thin and hyperechoic. The tendon is surrounded by a hypervascular area related to inflammation of the rotator cuff interval.
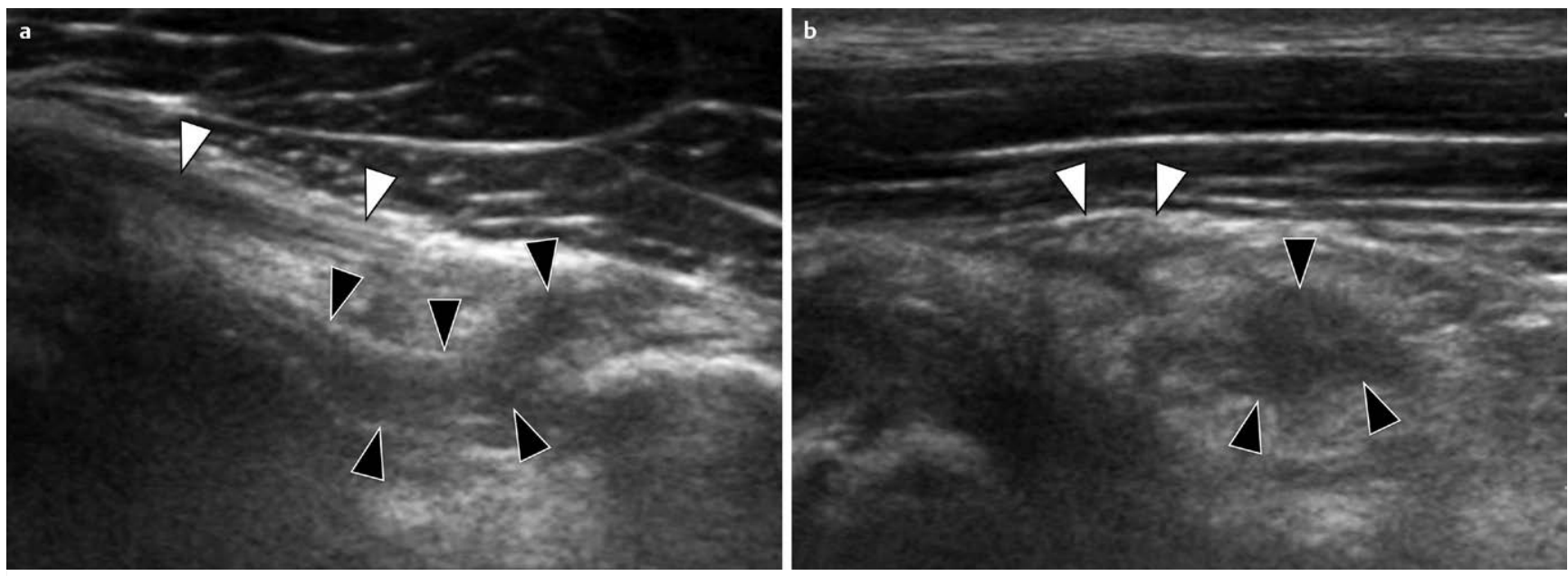

- Fig. 13 Adhesive capsulitis phase 2. Transverse $\mathbf{a}$ and longitudinal oblique $\mathbf{b}$ images obtained over the anterior aspect of the shoulder in a relaxed neutral position with flexed elbow and supinated forearm. Images show the coracohumeral ligament (black arrowheads) that is thickened and hypoechoic. The normal coracoacromial ligament is thin and hyperechoic (white arrowheads). 

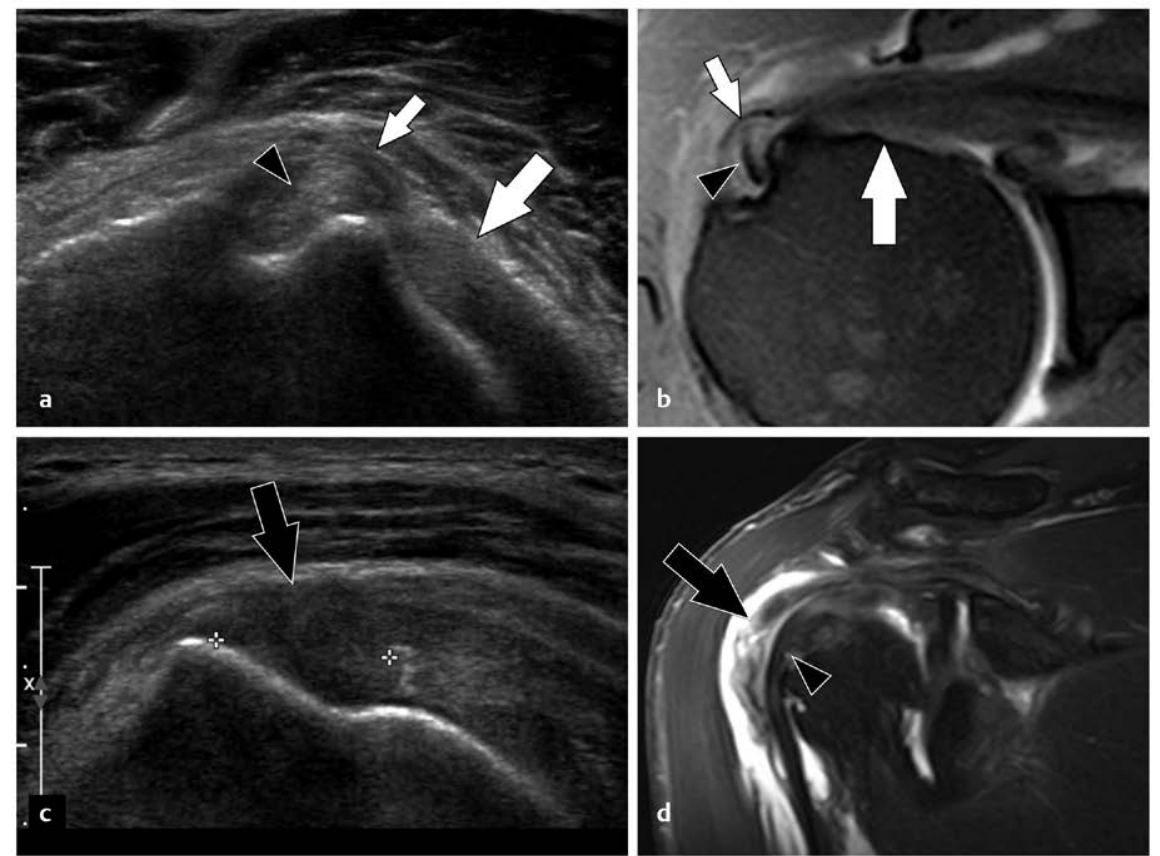

- Fig. 14 Tear of the supraspinatus and posterior bundle of the coracohumeral ligament (CHL). Transverse a and longitudinal oblique $\mathbf{c}$ images in a modified Crass position and corresponding MR images obtained over the anterior aspect of the shoulder. Images show medial subluxation of the long head of the biceps tendon (black arrowheads) due to tear on the anterior CHL bundle and supraspinatus (black arrows). The anterior bundle of the $\mathrm{CHL}$ and the glenohumeral ligament (white arrows) are continuous and retain the tendon to dislocate completely.
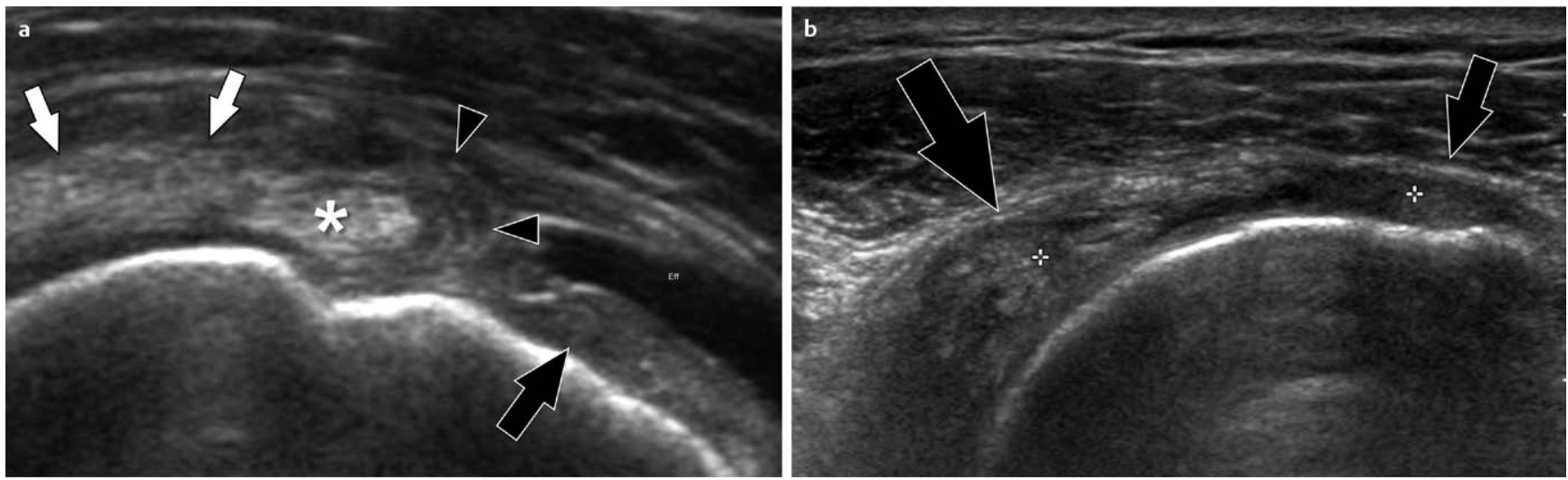

- Fig. 15 Tear of the subscapularis tendon associated with a partial tear of the anterior sling. Longitudinal a and transverse $\mathbf{b}$ oblique images obtained respectively over the rotator cuff interval and anterior aspect of the shoulder. In a, note the irregularly thickened anterior sling (black arrowheads) suggesting a partial tear. The long head of the biceps tendon (asterisk) and the supraspinatus tendon (white arrows) are normal. Note the absence of instability of the long head of the biceps tendon. An anechoic fluid collection (Eff) is located close to the subscapularis tendon (small black arrow) which appears thin and hypoechoic. In $\mathbf{b}$, a complete tear of the subscapularis tendon is evident (calipers). Note the larger retracted tendon stump (large arrow) and the smaller distal stump (small arrow).

In the modified crass position $>$ Fig. $\mathbf{5}$, we have an excellent view to evaluate the supraspinatus (SSP) enthesis (footprint at the greater tubercle), the ligaments and the humeral cartilage. All structures, especially the supraspinatus, should be visualized in the longitudinal and transverse view from anterior (subscapularis tendon, long biceps tendon) to posterior (infraspinatus tendon, teres minor tendon). The hyperechoic fibrillar rotator cable is a thin fibrous band continuous with the coracohumeral ligament that courses along the undersurface of the rotator cuff fibers and superficial to the joint capsule and can be visualized $1.5 \mathrm{~cm}$ medial to the greater tubercle [41] > Fig. 10. Different layers of the supraspinatus tendon are shown in ₹ Fig. 11 according to different cadaveric studies $[45,46]$. The rotator cable can be visualized in up to $99 \%$ of cases $[41,47]$. On long axis scans, the rotator cable is visualized in its short axis as a hyperechoic transversely oriented bundle of fibers running perpendicular and deep to the SSP and ISP tendons, located approximately $1 \mathrm{~cm}$ medial to the rotator cuff footprint [40]. Medial to the bicipital groove, we identify the subscapularis ten- 

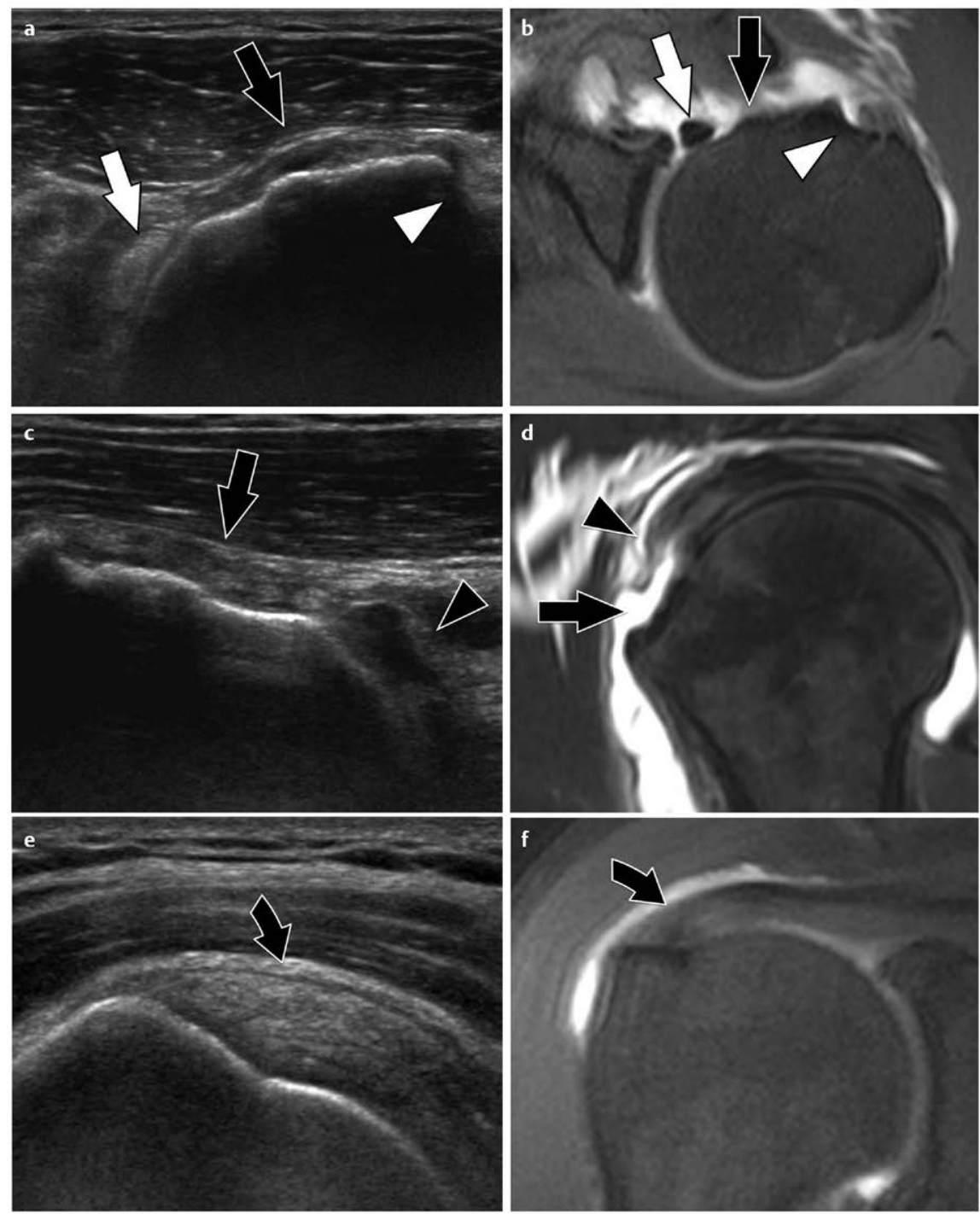

- Fig. 16 Tear of the subscapularis tendon associated with a complete tear of the anterior sling. Transverse a and longitudinal oblique $\mathbf{c}$ images obtained at the anterior face of the shoulder. Longitudinal oblique e image obtained over the supraspinatus tendon. Corresponding MR images b,d,f). In a, b, note the complete tear of the subscapularis tendon (black arrow) associated with the intraarticular dislocation of the long head of the biceps (white arrows). The white arrowheads point to the empty biceps groove. In c, d, longitudinal US and MRI images show the tear of the anterior sling (black arrowheads). In e, f, the supraspinatus tendon is normal.

don (SSC) and the superior glenohumeral ligament in external rotation.

The RI may reflect the condition of the glenohumeral joint and may be distended due to intra-articular effusion, capsulitis or synovitis [43]. Pathologic changes at the RI are common. A selection of changes is listed in $>$ Table 1. In adhesive capsulitis ( $\triangleright$ Fig. 12,13), for example, arthroscopy and histological studies revealed thickening of the ligaments of the RI, a shortened anterosuperior portion of the capsule with concomitant synovitis [48] or a contraction of the rotator interval [49] with replacement of the normal RI fat by fibrous tissue [50]. Another representative example is the combined pulley and rotator cuff lesion ( $>$ Fig. 14-16). Arthroscopic studies could demonstrate that for instance of all diagnosed subscapularis tears, $47 \%$ involved the medial pulley
(SGHL/MCHL complex) and of all rotator cuff tears involving the supraspinatus tendon, $10 \%$ involved the lateral pulley (LCHL) $[32,49]$.

\section{Summary}

This article demonstrates the capability of MSUS to visualize the detailed anatomy of the rotator interval. MSUS has a higher spatial resolution than other imaging techniques, the ability to examine these structures dynamically and to utilize the probe for precise anatomic localization of the patient's pain by sono-palpation. Obviously, MSUS is limited with respect to visualizing the more proximal intra-articular aspect of the components of the RI and when the structures are obscured by overlying bone such as the acromion. Since pathologic changes are common in this region, it is im- 
portant to acquire the necessary technical ability. Routine MSUS imaging of the rotator interval will amplify our diagnostic ability in rheumatology patients with shoulder pain and improve our diagnostic accuracy. So, we not only need to consider bursitis, synovitis and tendonitis, but we also need to become proficient in detecting capsulitis and the wide array of rotator cuff tears with or without additional lesions of the ligaments and joint capsule in this critical region.

\section{Conflict of Interest}

The authors declare that they have no conflict of interest.

\section{Acknowledgements}

We would like to thank Stefano Bianchi for providing selected pathological images.

\section{References}

[1] Micheroli R, Kyburz D, Ciurea A, Dubs B, Bisig SP, Tamborrini G. Correlation of findings in clinical and high resolution ultrasonography examinations of the painful shoulder. J Ultrason 2015; 15: 29-44

[2] Hashefi M. Ultrasound in the diagnosis of noninflammatory musculoskeletal conditions. Ann N Y Acad Sci 2009; 1154: 171-203

[3] Nofsinger C, Konin JG. Diagnostic ultrasound in sports medicine: Current concepts and advances. Sports Med Arthrosc 2009; 17: 25-30

[4] Yablon CM, Bedi A, Morag Y, Jacobson JA. Ultrasonography of the shoulder with arthroscopic correlation. Clin Sports Med 2013; 32: 391-408

[5] Teefey SA, Rubin DA, Middleton WD, Hildebolt CF, Leibold RA, Yamaguchi K. Detection and quantification of rotator cuff tears. Comparison of ultrasonographic, magnetic resonance imaging, and arthroscopic findings in seventy-one consecutive cases. J Bone Joint Surg Am 2004; 86-A: 708-16

[6] lannotti JP, Ciccone J, Buss DD, Visotsky JL, Mascha E, Cotman K, Rawool NM. Accuracy of office-based ultrasonography of the shoulder for the diagnosis of rotator cuff tears. J Bone Joint Surg Am 2005; 87: 1305-11

[7] Al-Shawi A, Badge R, Bunker T. The detection of full thickness rotator cuff tears using ultrasound. J Bone Joint Surg Br 2008; 90: 889-92

[8] van Holsbeeck MT, Kolowich PA, Eyler WR, Craig JG, Shirazi KK, Habra GK, Vanderschueren GM, Bouffard JA. US depiction of partial-thickness tear of the rotator cuff. Radiology 1995; 197: 443-6

[9] Stegbauer ], Rump LC, Weiner SM. Sites of inflammation in painful rheumatoid shoulder assessed by musculoskeletal ultrasound and power Doppler sonography. Rheumatol Int 2008; 28: 459-65

[10] Harryman DT, Sidles JA, Harris SL, Matsen FA. The role of the rotator interval capsule in passive motion and stability of the shoulder. J Bone Joint Surg Am 1992; 74: 53-66

[11] Gaskill TR, Braun S, Millett P]. Multimedia article. The rotator interval: pathology and management. Arthroscopy 2011; 27: 556-67

[12] Burkhart SS, Esch JC, Jolson RS. The rotator crescent and rotator cable: an anatomic description of the shoulder's 'suspension bridge'. Arthroscopy 1993; 9: 611-6
[13] Scofienza LM, Orlandi D, Fabbro E, Pucci S, Silvestri E. High-resolution ultrasound (HRUS) evaluation of the rotator cable (RCa) in young and elderly asymptomatic volunteers. ECR Meet 2010;

[14] Thompson WO, Debski RE, Boardman ND, Taskiran E, Warner J], Fu $\mathrm{FH}$, Woo SL. A biomechanical analysis of rotator cuff deficiency in a cadaveric model. Am J Sports Med 24: 286-92

[15] Malicky DM, Soslowsky LJ, Blasier RB, Shyr Y. Anterior glenohumeral stabilization factors: Progressive effects in a biomechanical model. J Orthop Res 1996; 14: 282-8

[16] Seibold CJ, Mallisee TA, Erickson S], Boynton MD, Raasch WG, Timins ME. Rotator cuff: Evaluation with US and MR imaging. Radiographics 19: 685-705

[17] Jost B, Koch PP, Gerber C. Anatomy and functional aspects of the rotator interval. J Shoulder Elbow Surg 9: 336-41

[18] Ho CP. MR imaging of rotator interval, long biceps, and associated injuries in the overhead-throwing athlete. Magn Reson Imaging Clin N Am 1999; 7: 23-37

[19] Lee JC, Guy S, Connell D, Saifuddin A, Lambert S. MRI of the rotator interval of the shoulder. Clin Radiol 2007; 62: 416-23

[20] Sethi N, Wright R, Yamaguchi K. Disorders of the long head of the biceps tendon. J Shoulder Elbow Surg 8: 644-54

[21] Habermeyer P, Magosch P, Pritsch M, Scheibel MT, Lichtenberg S. Anterosuperior impingement of the shoulder as a result of pulley lesions: A prospective arthroscopic study. J Shoulder Elbow Surg 13: 5-12

[22] Cole B], Rodeo SA, O’Brien SJ, Altchek D, Lee D, DiCarlo EF, Potter H. The anatomy and histology of the rotator interval capsule of the shoulder. Clin Orthop Relat Res 2001; 129-37

[23] Yang H, Tang K, Chen W, Dong S, Jin T, Gong J, Li J, Wang H, Wang J, $\mathrm{Xu}$ J. An anatomic and histologic study of the coracohumeral ligament. J Shoulder Elbow Surg 18: 305-10

[24] Neer CS, Satterlee CC, Dalsey RM, Flatow EL. The anatomy and potential effects of contracture of the coracohumeral ligament. Clin Orthop Relat Res 1992; 182-5

[25] Keene DR, Sakai LY, Burgeson RE. Human bone contains type III collagen, type VI collagen, and fibrillin: Type III collagen is present on specific fibers that may mediate attachment of tendons, ligaments, and periosteum to calcified bone cortex. J Histochem Cytochem 1991; 39: 59-69

[26] Franchi M, Trirè A, Quaranta M, Orsini E, Ottani V. Collagen structure of tendon relates to function. ScientificWorldjournal 2007; 7: 404-20

[27] Arai R, Nimura A, Yamaguchi K, Yoshimura H, Sugaya H, Saji T, Matsuda S, Akita K. The anatomy of the coracohumeral ligament and its relation to the subscapularis muscle. J Shoulder Elbow Surg 2014; 23: $1575-81$

[28] Shankman S, Bencardino J, Beltran J. Glenohumeral instability: evaluation using MR arthrography of the shoulder. Skeletal Radiol 1999; 28: 365-82

[29] D. AF. Surgery of the Shoulder: $9780397504923:$ Medicine \& Health Science Books

[30] Krzyżanowski W. The use of ultrasound in the assessment of the glenoid labrum of the glenohumeral joint. Part I: Ultrasound anatomy and examination technique. J Ultrason 2012; 12: 164-77

[31] Yamaguchi WG, Bindra K. R. Disorders of the biceps tendon. In: lannotti JP. Complex and Revision Problems in Shoulder Surgery: 9780781746588. Medicine \& Health Science Books

[32] Braun S, Horan MP, Elser F, Millett PJ. Lesions of the biceps pulley. Am J Sports Med 2011; 39: 790-5

[33] Bennett WF. Subscapularis, medial, and lateral head coracohumeral ligament insertion anatomy. Arthroscopic appearance and incidence of 'hidden' rotator interval lesions. Arthroscopy 2001; 17: 173-80 
[34] Curtis AS, Snyder SJ. Evaluation and treatment of biceps tendon pathology. Orthop Clin North Am 1993; 24: 33-43

[35] MacDonald K, Bridger ], Cash C, Parkin I. Transverse humeral ligament: Does it exist? Clin Anat 2007; 20: 663-7

[36] Moser TP, Cardinal É, Bureau N], Guillin R, Lanneville P, Grabs D. The aponeurotic expansion of the supraspinatus tendon: Anatomy and prevalence in a series of 150 shoulder MRIs. Skeletal Radiol 2015; 44: 223-31

[37] Gleason PD, Beall DP, Sanders TG, Bond JL, Ly JQ, Holland LL, Pasque CB. The transverse humeral ligament: A separate anatomical structure or a continuation of the osseous attachment of the rotator cuff? Am J Sports Med 2006; 34: 72-7

[38] Nakata W, Katou S, Fujita A, Nakata M, Lefor AT, Sugimoto H. Biceps pulley: Normal anatomy and associated lesions at MR arthrography. Radiographics 31: 791-810

[39] Kolts I, Busch LC, Tomusk H, Arend A, Eller A, Merila M, Russlies M. Anatomy of the coracohumeral and coracoglenoidal ligaments. Ann Anat 2000; 182: 563-6

[40] Denard PJ, Koo SS, Murena L, Burkhart SS. Pseudoparalysis: The importance of rotator cable integrity. Orthopedics 2012; 35: e1353-7

[41] Morag Y, Jacobson JA, Lucas D, Miller B, Brigido MK, Jamadar DA. US appearance of the rotator cable with histologic correlation: preliminary results. Radiology 2006; 241: 485-91

[42] Morag Y, Jamadar DA, Boon TA, Bedi A, Caoili EM, Jacobson JA. Ultrasound of the rotator cable: prevalence and morphology in asymptomatic shoulders. AJR Am J Roentgenol 2012; 198: W27-30
[43] Tamborrini G, Marx C, Müller AM, Szöllösy G, Draghi FSt Bianchi et al. Ultrasound, Anatomy and Arthroscopy of the Shoulder: high resolution sonoanatomy, sonohistology and sonopathology atlas - anatomy and arthroscopy of the shoulder, 3nd ed. 2017;

[44] Rozin AP, Toledano K, Dagan A, Balbir-Gurman A. Ultrasound investigation of the glenohumeral joint by anterior access in patients with rheumatoid arthritis and healthy controls. Med Sci Monit 2015; 21: $533-41$

[45] Dugas JR, Campbell DA, Warren RF, Robie BH, Millett PJ. Anatomy and dimensions of rotator cuff insertions. J Shoulder Elbow Surg 11: 498-503

[46] Clark JM, Harryman DT. Tendons, ligaments, and capsule of the rotator cuff. Gross and microscopic anatomy. J Bone Joint Surg Am 1992; 74: 713-25

[47] Kask K, Kolts I, Lubienski A, Russlies M, Leibecke T, Busch LC. Magnetic resonance imaging and correlative gross anatomy of the ligamentum semicirculare humeri (rotator cable). Clin Anat 2008; 21: 420-6

[48] Warner JJ, Allen A, Marks PH, Wong P. Arthroscopic release for chronic, refractory adhesive capsulitis of the shoulder. J Bone Joint Surg Am 1996; 78: 1808-16

[49] Vinson EN, Major NM, Higgins LD. Magnetic resonance imaging findings associated with surgically proven rotator interval lesions. Skeletal Radiol 2007; 36: 405-10

[50] Rodeo SA, Hannafin JA, Tom J, Warren RF, Wickiewicz TL. Immunolocalization of cytokines and their receptors in adhesive capsulitis of the shoulder. J Orthop Res 1997; 15: 427-36 